\title{
Biochemical Activity of Micro-organisms Isolated from Various Regions of the World Ocean
}

\author{
By A. E. KRISS, I. E. MISHUSTINA AND E. V. ZEMTSOVA \\ Institute of Microbiology, Academy of Sciences, U.S.S.R., 33 Lininsky Prospect, \\ Moscow, U.S.S.R.
}

(Received 22 November 1961)

\begin{abstract}
SUMMARY
There were found considerably fewer biochemically active microorganisms among heterotrophs inhabiting the equatorial-tropical zone of the World Ocean than in the high latitude area. Many micro-organisms with many-sided enzymic activities were present in the microbial population of the near-polar area, determining more profound transformations of organic matter in the waters of these areas as compared with the tropical area and consequently an increased concentration of biogenic substances. It is suggested that there is a unique exchange between the areas of low latitudes and those of high latitudes in the World Ocean. Currents driving equatorial-tropical waters to the north and south carry with them organic matter, chiefly allochthonous in origin; this material is more completely decomposed by the microbial species which inhabit high latitudes. The liberated biogenic substances are carried by currents into the depths of other geographic areas, thus increasing the reserve of substances taking part in the primary production of organic matter in these areas of the World Ocean.
\end{abstract}

\section{INTRODUCTION}

Microbiological investigations in the Indian, Atlantic and Pacific Oceans, in the Central Arctic, Norwegian and Greenland Seas and in the seas of the Antarctic, made it possible to accumulate data on the quantitative distribution (Kriss, Abyzov, Lebedeva, Mishustina \& Mitskevitch, 1960) and species composition of the microbial population in the World Ocean.

The ultrafiltration method (Kriss, 1959) was used to obtain cultures of microorganisms inhabiting the seas and oceans examined. The primary treatment of the water and mud samples was done in the microbiological laboratory on board ship immediately after collection. Water samples were filtered through membrane filters which subsequently were placed on nutrient agar (tryptic hydrolysate of fish flour, 50 g.; ocean water, $1000.0 \mathrm{ml}$.). Mud suspensions were inoculated on this agar in appropriate dilutions. The colonies were transferred to agar slopes of the same composition; often representatives of dissimilar colonies were taken. The test tubes were kept in the ship's laboratory until visible growth appeared; after this they were stored in a refrigerator $\left(+2^{\circ}\right.$ to $\left.+4^{\circ}\right)$ till the expedition came to an end.

Thus a collection of over 4000 strains of heterotrophic micro-organisms was obtained. This collection reflected the composition of the microbial population in various places of the World Oceans, i.e. from the North Pole to the Antarctic coast and at different depths, from the surface down to the bottom. The whole collection, 
with the exception of strains which did not survive, was investigated from the standpoint of the capacity of strains to metabolize proteins and carbohydrates and to use bound oxygen and inorganic nitrogen compounds. This was of significance not only for the species characteristics of the microbial forms found in the World Ocean, and which can grow in laboratory conditions on artificial nutrient media of organic or inorganic composition, but also for obtaining some idea of the biochemical activity of these microbial species in decomposing readily assimilable forms of organic matter in seas and oceans.

\section{METHODS}

Proteolytic activity was studied on meat-peptone gelatine, meat-peptone broth, and milk. During 15 days after inoculation, gelatine liquefaction, milk coagulation and peptonization, and ammonia and hydrogen sulphide formation in broth were recorded. Ammonia was detected by a litmus paper strip and hydrogen sulphide by the blackening of a lead acetate paper. The two paper strips were fixed to a cotton-wool stopper of a test tube.

The reddening of peptone water + azolitmin (peptone, $1 \%$; azolitmin, $0.02 \%$ ) containing the following carbohydrates (1\%): glucose, sucrose, maltose, lactose, mannitol, was taken to indicate fermentation. Uncoloured zones around the streak on potato agar, after treatment with Lugol's iodine solution, pointed to the ability of a strain to decompose starch. Czapek's medium (g.: $\mathrm{K}_{2} \mathrm{HPO}_{4}, 0.5 ; \mathrm{MgSO}_{4}, \mathbf{0 . 5}$; $\mathrm{NaCl}, 0.5 ; \mathrm{KNO}_{3}, 1.0 ; \mathrm{CaCO}_{3}, 2$; sucrose, 20.0 ; agar, $20.0 ; \mathrm{FeSO}_{4}$, trace; distilled water, $1000.0 \mathrm{ml}$.) was used to establish whether mineral sources of nitrogen were utilized and whether nitrates were reduced to nitrites.

When growth was not observed, sea salt was added to meat-peptone gelatine, milk, peptone water with carbohydrates, potato agar, or Czapek's medium with an inorganic source of nitrogen, the content of sea salt in a medium then being $2 \%$.

\section{RESULTS}

Over 500 strains (17\% of the collection) brought about clear hydrolysis of protein (gelatine, milk proteins; Table 1). Much decomposition of protein with the formation of hydrogen sulphide was observed in $4 \%$ of cultures. According to ZoBell \& Upham (1944) from 60 strains isolated from the Pacific Ocean water and mud off the Californian coast, 30 hydrolysed casein and 47 liquefied gelatine. The greater percentage of proteolytic strains in ZoBell \& Upham's investigations might be due to their organisms having been isolated from the coastal zone of the Pacific Ocean. The same reasons may have been responsible for the predominance of strains liquefying gelatine (451 of the total of 733 cultures) in the collection of microorganisms isolated from the Black Sea (Kriss, Markianovich \& Rukina, 1954). The Black Sea is an intracontinental basin with a considerable continental effluent.

Table 1 shows the activity of bacterial cultures obtained in ocean areas with regard to carbohydrate dissimilation with the formation of acid. The highest percentage of strains $(26.4 \%)$ fermented glucose, acidifying the medium. The formation of acid in the media with sucrose or maltose was observed in about the same proportion of cultures (18-19\%). Then followed mannitol (15\%) and lactose $(10 \%)$. These data indicate only the capacity of the cultures from the oceanic collection to ferment some carbohydrates and mannitol with the formation of acids. The overwhelming majority of strains ( $>80 \%$ ) grew in media with glucose, sucrose, 
maltose, lactose, or mannitol. Similar results were obtained in the medium with starch as carbon source. However, the percentage of strains hydrolysing starch was comparatively great $(63 \cdot 3 \%)$.

ZoBell \& Upham (1944) reported that $75 \%$ of strains in their collection fermented glucose with acid formation. Among the Black Sea cultures the percentage decomposing glucose, maltose, sucrose, lactose or mannitol giving acid was also considerably greater than among strains in the oceanic collection.

Of 3158 strains of micro-organisms found in various ocean areas 2873 grew on the medium with a mineral source of nitrogen (Table 1). However, only $40 \%$ of the strains reduced nitrate. The percentage of Black Sea strains which reduced nitrate to nitrite was about the same: about $30 \%$ of the whole collection.

Differences in the numbers of microbial forms from the Atlantic, Indian and Pacific Oceans, which hydrolysed protein and dissimilated carbohydrate are noteworthy. The percentage of strains which hydrolysed gelatine or casein, decomposed protein to give hydrogen sulphide, and fermented glucose, sucrose, maltose or mannitol with acid formation, was highest in the Atlantic Ocean and lowest in the Pacific Ocean. In this respect the Indian Ocean samples were intermediate. Table 1 shows the range of these quantitative differences. In the Pacific Ocean the percentage of strains which liquefied gelatine, formed hydrogen sulphide from meatpeptone broth, and peptonized milk coagulation was 4 to 5 times lower than in the Atlantic Ocean. The percentage of strains forming acid from carbohydrates and mannitol was 2 or 3 times to 5 times higher in the Atlantic Ocean as compared with the Pacific Ocean.

Since nearly all the water samples were collected far from land, at various depths in open areas of the Atlantic, Indian, and Pacific Oceans, it is suggested that the differences reflect not the microbiological specificity of these parts of the World Ocean but are influenced by geographic factors.

The map (Fig. 1) shows that in the Atlantic Ocean the studies were made mainly in high latitudes including areas adjacent to the Arctic Ocean, while in the Pacific Ocean the stations were only in the subtropical, tropical, and equatorial areas. Microbiological sections crossed all geographic zones from the north tropical region to the Antarctic region in the Indian Ocean.

A more detailed study clearly showed geographical regularities in the distribution of biochemically active and inactive species of heterotrophs in the World Ocean. In the Indian Ocean, the greatest percentage of proteolytic cultures was found in the high latitude areas (Table 2). The percentage of cultures which liquefied gelatine and peptonized and decomposed protein with hydrogen sulphide formation was a few times higher in the Antarctic and sub-Antarctic areas than in the equatorial zone. The same correlation was observed in the percentage of strains which fermented carbohydrates among the cultures from the Antarctic seas and from tropical zones.

Similar results were obtained with samples from the Atlantic Ocean: there was a greater percentage of strains which hydrolysed protein and fermented carbohydrates in the sub-Arctic and arctic area samples than in the tropical samples (Table 3).

The biochemical activity of the great majority of cultures in the Pacific Ocean collection was not high. Investigations in the Pacific Ocean proved that the proteolytic and fermentative activities of the microbial population were comparatively weak in the low latitude areas of the World Ocean. It is noteworthy that the scarcity 


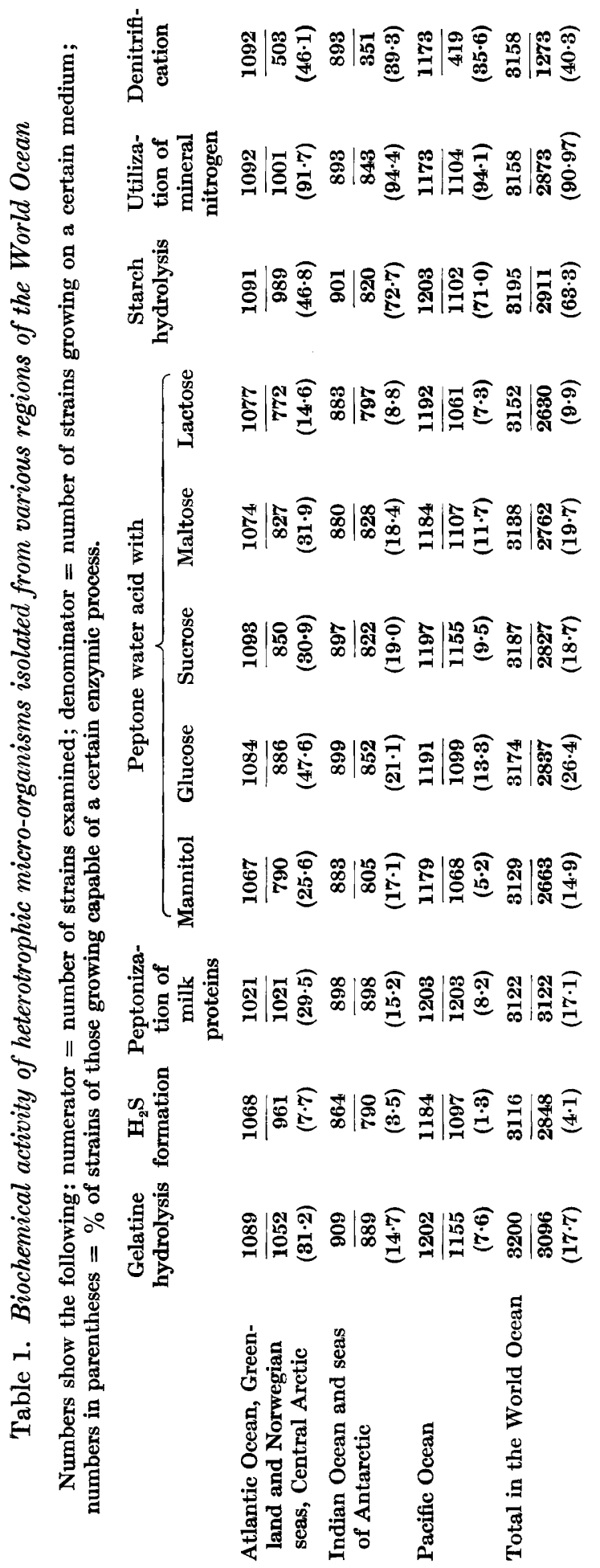




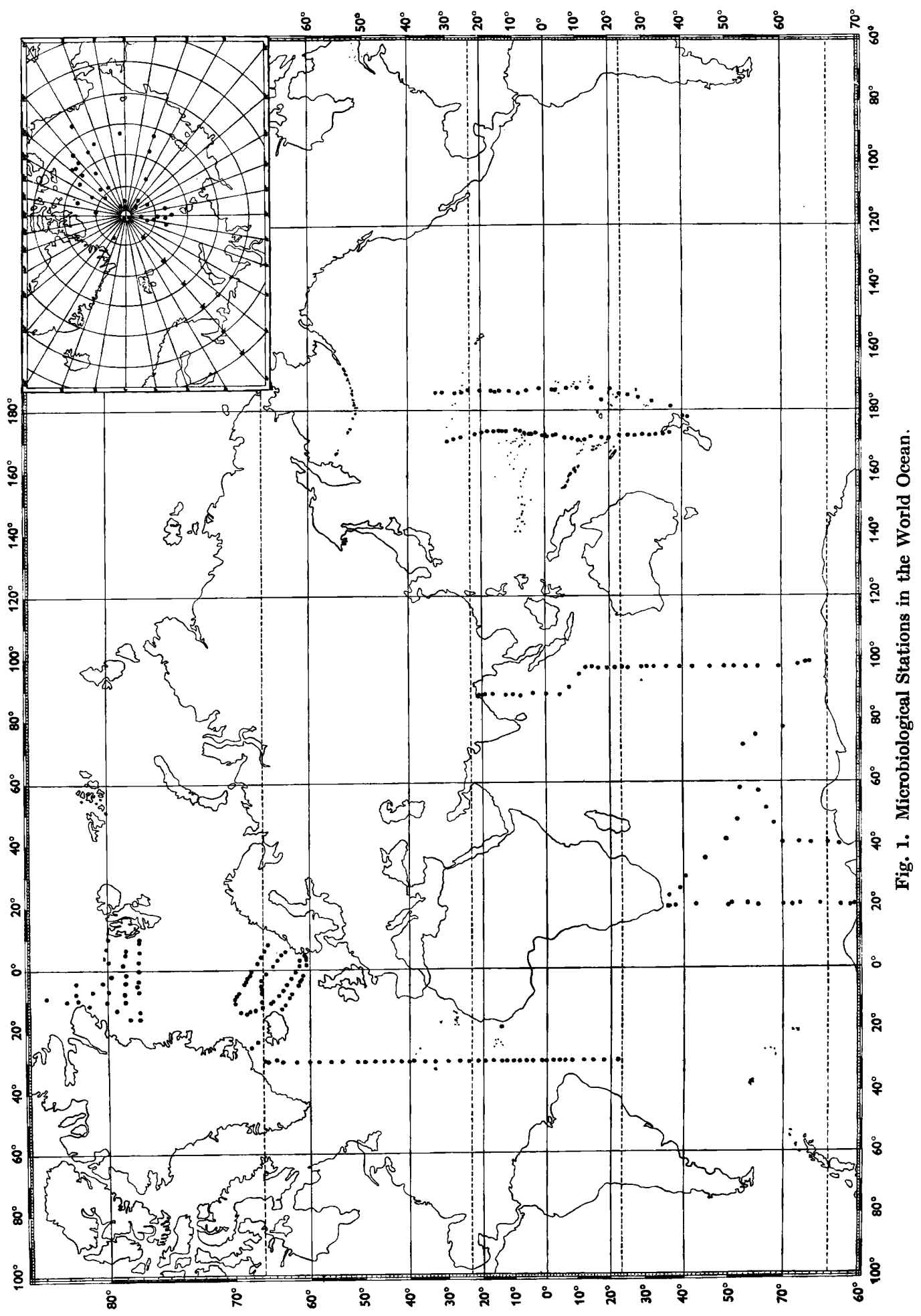




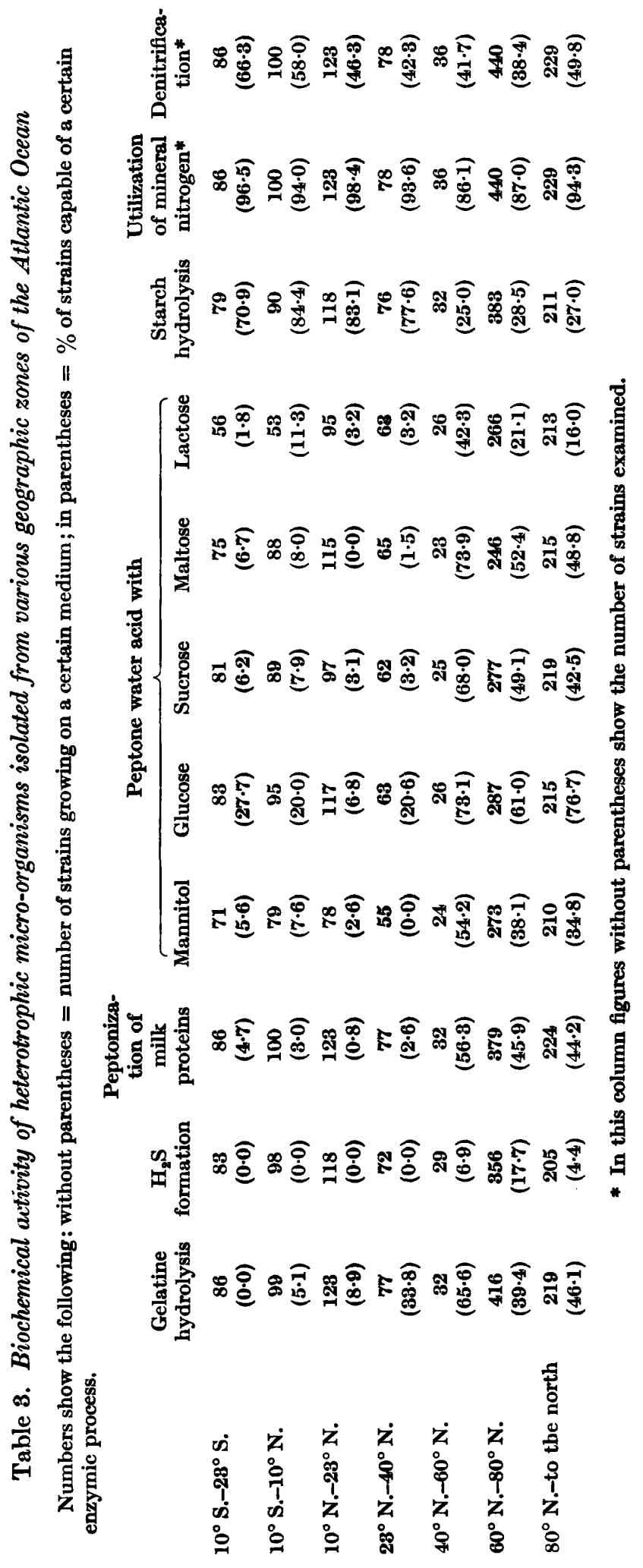


of biochemically active microbial species separates the northern subtropical zone in the section along $172^{\circ} \mathrm{E}$. (Table 4) from the northern subtropical zone in the section along $174^{\circ} \mathrm{W}$. (Table 5) and from the southern subtropical zones in both sections. In the northern subtropical zone, the microbiological stations were worked in the area of the powerful Kuroshio current which is a branch of the north-equatorial current, poor in biochemically active heterotrophs.

Most of the microbial cultures from the equatorial-tropic zone hydrolysed starch. The percentage of cultures which hydrolysed starch was lower in the high latitudes of the Indian and Atlantic Oceans.

The differences in the number of denitrifying micro-organisms in various geographic zones of the World Ocean were negligible. The data obtained contradict Brandt's hypothesis (Brandt, 1904) which suggests the activities of micro-organisms which reduce nitrate and nitrite as the reason for scarce plant life in the tropical areas. The percentage of denitrifiers found in the equatorial-tropical area was not greater than in the subarctic and subantarctic areas where the water is most rich in phytoplankton.

The considerable percentage of strains which utilize inorganic nitrogen and which are about equal in all the geographic zones of the World Ocean is noteworthy. Of the cultures examined $86-99 \%$ developed well on media with an inorganic nitrogen source.

Since microbiological sections crossed the equatorial-tropical area four times (twice in the Pacific Ocean, once in the Indian Ocean, and once in the Atlantic Ocean), the northern subtropical zone three times (twice in the Pacific Ocean and once in the Atlantic Ocean) and the southern subtropical zone three times (twice in the Pacific Ocean and once in the Indian Ocean), it was of interest to compare the biochemical activity of heterotrophs in various geographic zones of the whole World Ocean. Table 6 shows that the equatorial-tropical zone of the World Ocean is distinguished by very few microbial species which decompose protein and ferment carbohydrate. In the Arctic, sub-Arctic, Antarctic, and sub-Antarctic areas the percentage of strains which decompose protein is 4 to 60 times greater, and the percentage of strains which ferment mannitol, glucose, sucrose, maltose or lactose 2 to 11 times greater than in the equatorial zone. These data show that the processes of organic matter decomposition and the liberation of biogenic elements are more vigorous in high latitudes. Although the number of heterotrophs there is not as great as near the equator, and their biochemical activity is influenced by low temperatures, the presence of comparatively great numbers of microbial forms with many-sided enzymic activity determines, however, more profound transformations of organic matter in high latitudes than in tropical areas. Hence, the increased content of biogenic substances needed for the development of marine plant life in the Arctic, sub-Arctic, and sub-Antarctic areas of the World Ocean. In fact, considerable phytoplankton biomasses, which are many times greater than those in the tropical areas, are observed in these geographic zones. Evidently, a relative abundance of microbial forms in high latitude waters, producing versatile reactions in the decomposition of organic matter, results in increased concentrations of biogenic substances not only in the waters of these latitudes. These products of organic matter decomposition and transformation fill the depths of other areas of the World Ocean by virtue of the deep currents which penetrate to the lower latitudes. 


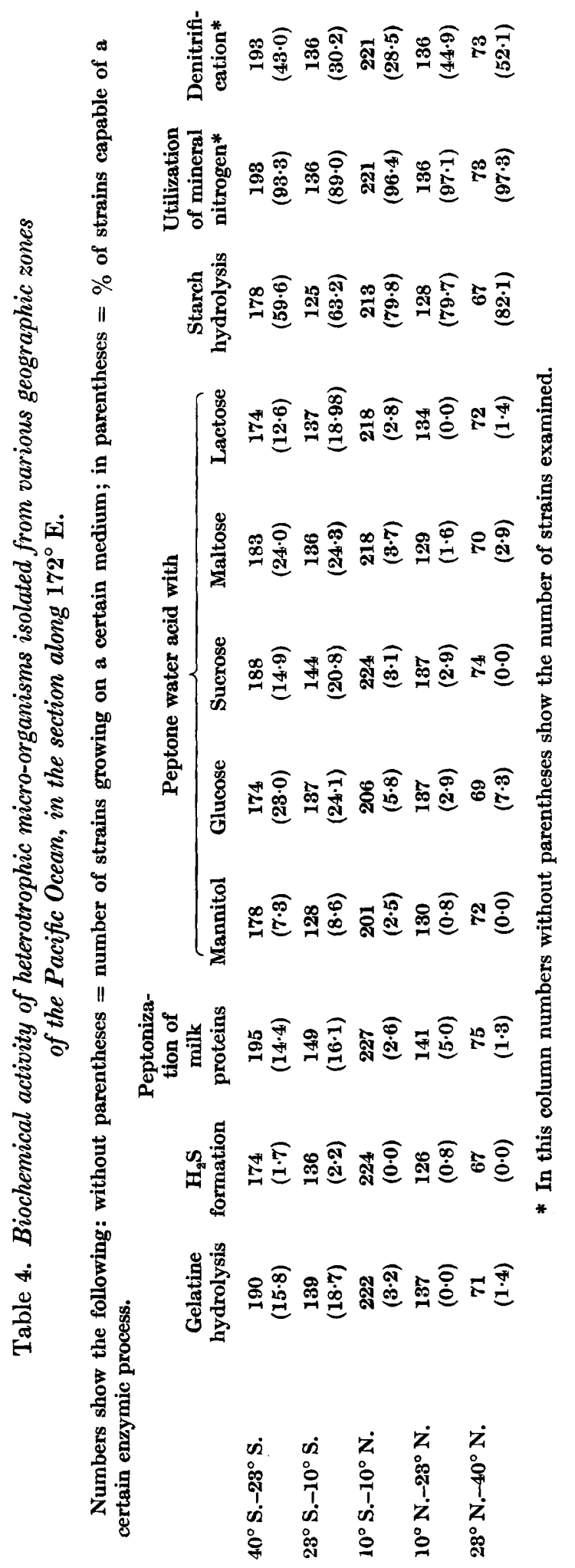




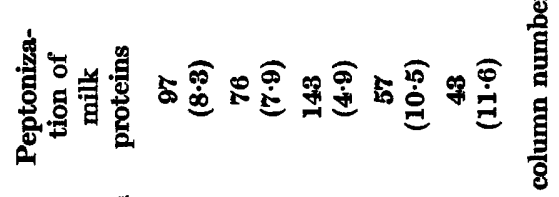

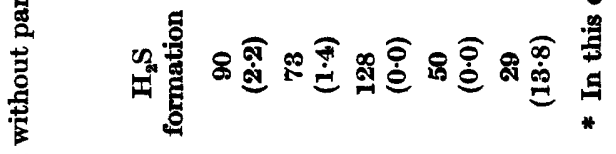




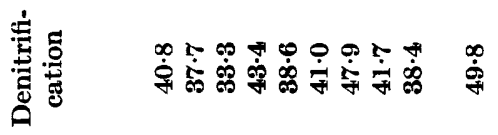

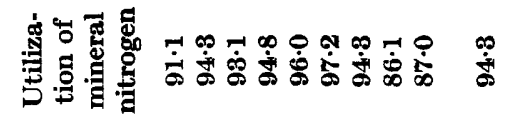

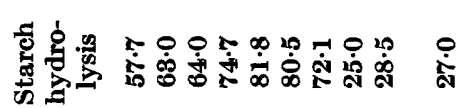

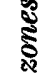

है:

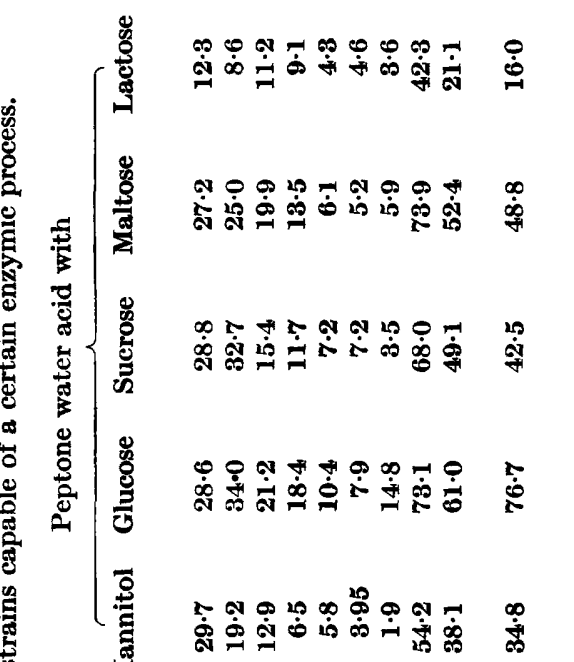

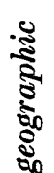

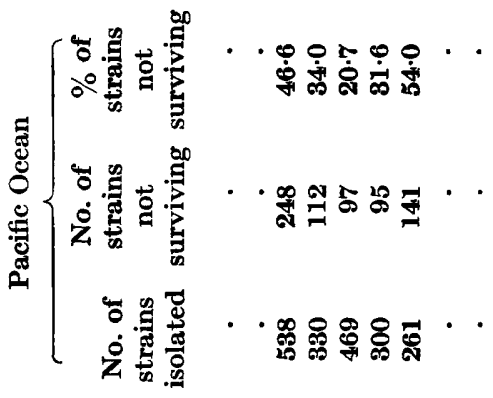

हैํำ

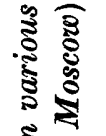

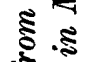

है

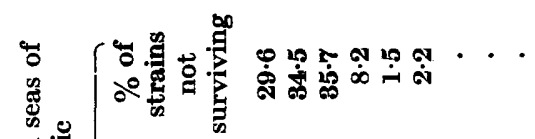

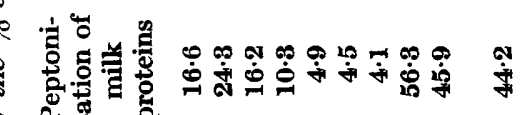

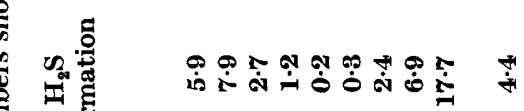

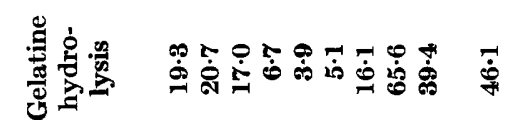

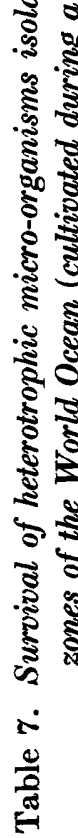

.

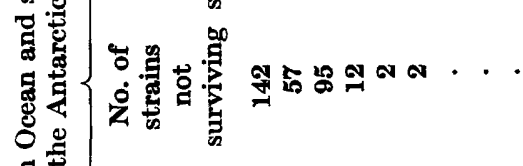

焉

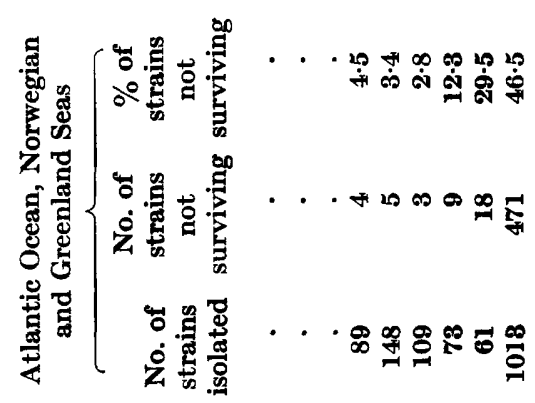

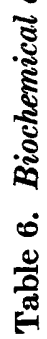

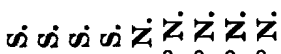

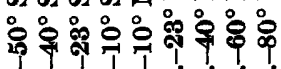

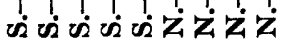

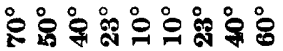

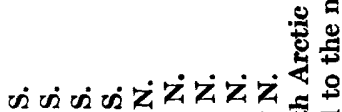

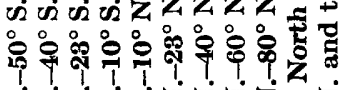

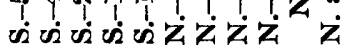

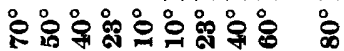




\section{A. E. Kriss, I. E. Mishustina and E. V. Zemtsova}

So far, the reasons for the scarcity of biochemically active microbial forms in tropical waters and their increased concentration in high latitude waters have not been elucidated. Possibly, a relatively high concentration of allochthonous organic matter in the tropical waters, which is easily assimilable by micro-organisms and which is the reason for a considerable density of heterotrophs in the equatorialtropic zone of the World Ocean, does not necessarily bring about enzymic reactions that would guarantee a full utilization of the organic matter. The scarcity of food resources in the high latitude waters may result in the adaptation of heterotrophs which allows a more economic use of organic substances at the expense of their more profound decomposition and transformation.

There was a notable connexion between the survival of marine heterotrophs under laboratory conditions and the geographic position from which the cultures were obtained. Table 7 shows data on the survival of heterotrophs obtained from various geographic zones of the Atlantic, Pacific and Indian Oceans. Taking into account that the time of cultivation in the laboratory was not the same for strains from the various areas of the World Ocean, only data from the first year's cultivation were taken for comparison. The percentage of death among strains from high latitudes was a few times higher than among cultures obtained in the equatorialtropical zone. In the Atlantic Ocean collection the percentage of dead cultures from the sub-Arctic and Arctic areas (Norwegian and Greenland Seas) was 6 to 15 times greater than among cultures obtained in low latitudes. About the same correlation was observed in comparing the percentage of deaths of strains from the equatorialtropical zone of the Indian Ocean and from the Antarctic seas. The percentage of cultures obtained in the equatorial zone that did not survive was about half those from subtropical areas of the Pacific Ocean.

Taking into consideration that the collection of heterotrophs from various areas of the World Ocean was made up, to a great extent, of micro-organisms inhabiting depths with about the same temperature in all geographic zones, it is hardly possible to suppose that a greater survival of strains from low latitudes was due to their better adaptation to the temperature conditions of the laboratory. It seems that a comparatively high percentage of the deaths of the strains from high latitudes was due to the fact that in the cultures of these heterotrophs, because of their manysided enzymic activities, there accumulated metabolic products mort harmful to microbes than those present in the less biochemically active cultures of heterotrophs from the equatorial-tropical zone.

\section{REFERENCES}

Brandt, K. (1904). Über die Bedeutung der Stickstoffverbindungen für die Produktion im Meere. Beih. bot. Zbl. 16, 383.

Kriss, A. E. (1959). Morskaya Microbiologia (glubokovodnaya) (Deep Sea Microbiology). Moscow-Leningrad.

Kriss, A., Abyzov, S., Lebedeva, M., Mishustina, I. \& Mitskevich, I. (1960). Geographic regularities in microbe population (heterotrophic) distribution in the world ocean. J. Bact. 80, 731 .

Kriss, A., Markianovich, E. \& Rukina, E. (1954). Noviye materiali o vidovom sostave mikroorganizmov Chernogo Morya. (New data on the species of micro-organisms in the Black Sea). Trav. Sta. biol. Sebastopol, 8, 220.

ZoBell, C. \& UphaM, H. (1944). A list of marine bacteria including descriptions of sixty new species. Bull. Scripps Inst. Oceanogr. 5, 239. 